\title{
Modeling of residual stress relaxation of fatigue in 2024-T351 aluminium alloy
}

\begin{abstract}
The initial induced compressive residual stresses relax during component operating life and it is important to consider the relaxation phenomenon in the design of the component. In this study, 2024-T 351 aluminium alloy specimens were shot peened under three different shotpeening intensities. Cyclic tests for two load magnitudes were performed for 1, 2, 10, 1000 and 10,000 cycles. The initial and final residual stresses and the cold work after each loading cycle were measured for the three shot-peening intensities and for the two load magnitudes using X-ray diffraction. The initial and final microhardnesses after each loading cycle load were also measured for the three shot-peening intensities. The results showed that the reduction in the residual stress, microhardness and cold work are dependent on the applied load. An empirical model was proposed to estimate the residual stress relaxation. The presented model incorporates parameters including the degree of cold work, initial induced residual stress and the number of applied loading cycles.
\end{abstract}

Keyword: Shot-peening; Residual stress; Residual stress relaxation 